\title{
Prevention as an Explicit Part of the Social Work Profession: A Systematic Investigation
}

\author{
Emily L. McCave \\ Carrie W. Rishel
}

\begin{abstract}
Historically, social workers have espoused a philosophy of prevention. However, this philosophy has not consistently translated into prevention-focused social work practice. This gap in social work practice is of concern given the growing federal attention placed on prevention efforts in key social work arenas, such as health, mental health, and substance abuse. In an effort to illustrate this practice gap, this article presents a systematic investigation of the status of prevention and social work through the examination of three seminal indicators including: the social work literature, the 2009-2012 National Association of Social Workers (NASW) Social Work Speaks, and the 2008 Educational Policy Accreditation Standards (EPAS). Results indicate that the social work profession lacks an emphasis on prevention, as well as cohesiveness regarding prevention across social work practice, education, and scholarship. Opportunities for integrating prevention into the profession are highlighted for key stakeholders, namely social work scholars, educators, and practitioners.
\end{abstract}

Keywords: Prevention, social work profession, social work literature, Social Work Speaks, EPAS

\section{INTRODUCTION}

The historical roots of the social work profession are grounded in a philosophy of prevention. Throughout our tenure as a profession, however, social workers have not consistently embraced prevention as a core component of practice (Bracht, 2000; Woody, 2006). Early commitment to prevention practice within the profession faded as social workers professionalized and established themselves as psychiatric case workers and mental health professionals (Trattner, 1999). Renewed interest in prevention-focused social work emerged in the 1960s, and again in the 1980s, but prevention has yet to become a firmly established focus of social work practice. While there have been areas within social work that have drawn from prevention principles, such as HIV/AIDS prevention, even within the arena of sexual health there has been a strong emphasis on the consequences of the sexual behavior (providing support to those with unplanned pregnancies or STDs) as opposed to a focus on prevention (Brashear, 1976; McCave, 2010). Although previous work has addressed the connection between prevention and social work at various points throughout our professional history, up to this point there has been no systematic analysis of the status of prevention in social work. The purpose of this article is to present the results of a systematic investigation of the prevalence of prevention in social work and to discuss the implications of these results for the current and future status of the profession.

Emily L. McCave, Ph.D., is an Assistant Professor and Carrie W. Rishel, Ph.D. is an Associate Professor, both in the Division of Social Work at the West Virginia University. The authors would like to thank Ashlea Shiflet for her consistent enthusiasm and high quality work in assisting with the preparation and editing of this article.

Copyright (c) 2011 Advances in Social Work Vol. 12 No. 2 (Fall 2011), 226-240 


\section{What is Prevention?}

As some social workers may not be familiar with prevention theory and concepts, it is important to briefly define and discuss prevention practice here. The goal of prevention practice is to prevent major problems of living. By definition, prevention occurs before a problem is fully visible or developed (National Research Council and Institute of Medicine, 2009). The prevention approach requires moving beyond the medical-based disease model, in which practitioners wait for an illness or problem to develop and then provide evidence-based treatment, to a practice philosophy that focuses on long-term healthy development. The salient question asked in this philosophy is, "What resources need to be put in place now to support this healthy development?” (National Research Council and Institute of Medicine, 2009).

Prevention science as a unique discipline was formally recognized in the 1980s (Shore, 1998). Since that time, the study of prevention has greatly increased. One notable example, the Institute of Medicine (IOM) report, Reducing the Risks for Mental Disorders: Frontiers for Preventive Intervention Research (Mrazek \& Haggerty, 1994), popularized a change in terminology regarding classification of prevention programs (Farmer \& Farmer, 2001). While the traditional classification system categorized prevention efforts as primary, secondary, or tertiary, the new classification system uses the terms universal, selective, and indicated. Universal prevention programs are targeted at the general public or an entire population group. Selective prevention efforts are aimed at those who are at an elevated risk for a particular problem as compared to the general population. Finally, indicated prevention efforts are aimed at high-risk individuals, usually those who already demonstrate signs or symptoms of the targeted problem, but in whom it has not yet fully developed (Rishel, 2007). It is important to note that the 1994 IOM report, and its recent 2009 update (National Research Council and Institute of Medicine, 2009) clearly specify that the term "prevention" should be used only to refer to intervention activities that occur prior to the full onset of a disorder or problem. Therefore, efforts that were previously labeled as secondary or tertiary prevention are now more appropriately considered as "treatment" or "rehabilitation" (Woody, 2006).

Prevention practice is the application of prevention principles and goals to interventions aimed at preventing individual and social problems. Prevention scholars agree that prevention practice and programs should focus on targeted predictors of illness or health, called risk factors and protective factors (Rishel, 2007). Risk factors are defined as circumstances that increase the likelihood of negative outcomes while protective factors are considered to decrease the likelihood of negative outcomes (Durlak, 1998; Smith \& Carlson, 1997). Risk and protective factors are typically categorized into three groups: individual factors, family factors, and environmental factors (Garmezy, 1985), representing the three levels defined by ecological systems theory (Bronfenbrenner, 1979).

\section{Why should Social Workers Focus on Prevention?}

While a prevention approach has long been promoted in the field of public health, and has more recently become encouraged in many areas of health care, other areas of 
practice have lagged behind. For example, in the area of mental health services, most resources available have been used for treatment and rehabilitative services with very little funding allocated for the prevention of mental health problems (Dulmus \& Wodarski, 1997). This may be changing, however, as the new report by the National Research Council and Institute of Medicine (2009) highlights the urgent need for a paradigm shift in the field of mental health. The report notes that, "interventions before the disorder occurs offer the greatest opportunity to avoid the substantial costs to individuals, families, and society that [mental health] disorders entail" (National Research Council and Institute of Medicine, 2009, p. 1). As key providers of mental health services, social work professionals have a vested interest in the future of mental health practice.

While good evidence regarding the effectiveness of prevention did not exist in the early years of our profession, scholars in the field of prevention science have made important advances in recent years in developing an empirical research base and rigorously evaluating prevention efforts. We now know much more than in the past about "what works" in prevention (Rishel, 2007). Although prevention interventions have been shown to be effective at reducing problems (please see Rishel, 2007 for a thorough discussion of the evidence supporting prevention practice), most practitioners do not use a prevention-oriented approach to practice. This makes sense considering that clinical training has historically focused on diagnostic assessment and treatment skills, and rarely includes prevention theory or discussion of successful prevention efforts (Beardslee, 1998). It, therefore, seems likely that the majority of practitioners are not prepared to incorporate prevention principles and theory into their practice, and do not approach individual cases with a prevention focus.

Social workers are uniquely positioned to lead the movement toward preventionfocused practice. Prevention scholars point toward the need for a bio-psycho-social approach to prevention practice that focuses on the interaction between person and environment (Beardslee, 1998; Coie et al., 1993; Kellam, Koretz, \& Moscicki, 1999). Social workers have long embraced the ecological, person-in-environment perspective as our hallmark approach to practice-well equipping the profession to lead the way in cultivating prevention-focused service delivery. In his editorial on prevention, Bracht (2000) reviews a number of factors that support a preventive approach to practice, but notes that the practice community has been slow to respond to "prevention pleas." He suggests that the "will to change needs to be rekindled" (p. 3). Social workers, who are trained to be change advocates, are well prepared to initiate and encourage a shift in policy and practice toward a preventive approach.

\section{What is the Historical Connection between Social Work and Prevention?}

From its inception, social workers have espoused prevention-focused goals and practice approaches. Jane Addams' community-based approach to practice was, at its heart, a prevention-oriented approach. While they may not have been labeled as such, early settlement house services (e.g. education, socialization opportunities, skills training) were delivered with the hopes of preventing individual and social problems within the community. The profession's primary mission is to enhance human well-being, both in 
terms of individual well-being in a social context as well as the well-being of society (National Association of Social Workers, 2010). Prevention, by definition, enhances human well-being by preventing major problems of living. Furthermore, the profession's values and goals, such as reducing health disparities among oppressed and vulnerable populations, are consistent with a preventive approach to practice (Bracht, 2000).

Despite the apparent "goodness-of-fit" between the mission and goals of the profession and prevention practice, throughout most of our professional history social workers as a whole have not promoted our services as prevention-focused (Woody, 2006). Review of the social work literature indicates sporadic episodes of particular interest in prevention in the 1960s (e.g. Deschin, 1968; Rapoport, 1961; Rice, 1962) and most heavily in the 1980s (e.g. Feldman, Stiffman, Evans, \& Orme, 1982; Geismar \& Lagay, 1985; Germain, 1982; Gilbert, 1982; Libassi \& Maluccio, 1986; Roskin, 1980; Siefert, 1983; Walsh, 1982; Whitman \& Hennelly, 1982). Then, a decade ago, a pair of editorials in Social Work in Health Care again raised the issue of prevention and social work (Bracht, 2000; Rosendberg \& Holden, 1999). In summarizing their thoughts on prevention, Rosendberg and Holden (1999) urged "social work educators, practitioners and researchers to engage in a dialogue to find ways to focus the profession away from pathology and towards prevention" (emphasis added; p. 9). Although results of specific prevention interventions have appeared in social work journals since this call (e.g. Ager, Parquet, \& Kreutzinger, 2008; Skiba, Monroe, \& Wodarski, 2004; Yampolskaya, Brown, \& Vargo, 2004), little "dialogue" or discussion of the role of prevention in the profession (or, conversely, the role of the social work profession in prevention efforts) has appeared in the social work literature (with the exception of Hawkins, 2006, Lurie \& Monahan, 2001, and Woody, 2006).

\section{METHODOLOGY}

In order to best assess the current status of prevention within the social work profession, a systematic strategy was employed to ascertain the explicit content of prevention within three seminal indicators within the social work profession. These included the social work scholarly literature, the most current National Association of Social Workers (NASW) Social Work Speaks, and the most current Educational Policy Accreditation Standards (EPAS) Curriculum guidelines for social work undergraduate and graduate programs developed by the Council on Social Work Education (CSWE). These three sources were selected because they represent the profession's focus, and allow for an examination of the explicit content of prevention across social work scholarship, practice, and education. While implicit prevention content is important

within these three sources and is likely connected to both the presence and absence of explicit prevention content, it is beyond the scope of this paper. Rather only the explicit, that is, irrefutable, prevention content was considered in this investigation.

\section{Assessing the Social Work Literature}

A review of the social work literature allowed for an examination of the prevalence of "prevention" and "social work" in past and current social work scholarship. The databases examined included Social Services Abstracts and Social Work Abstracts. These 
two databases were used because they were considered the most likely to include social work prevention-focused literature. All years within each database were searched, which were 1970-2010 for Social Services Abstracts, and 1960-2010 for Social Work Abstracts. It was decided that books within the authors' institutional library would not be considered, given the variance of collections between University libraries.

\section{Assessing Social Work Speaks}

Since 1955, NASW has published Social Work Speaks, which features NASW's official position on both professional and societal policy issues (National Association of Social Workers, 2009). The Delegate Assembly within NASW is responsible for the creation of the statements, with input from the NASW membership. Social Work Speaks is used by NASW to make policy recommendations at the national and state level. NASW also recommends this book for use in the social work curriculum, as either a main text or supplemental reading. Further, "Social workers developed the statements to serve as broad parameters for advocacy work and to help professionals who are concerned with social issues focus their thinking” (p. $x$ ). Social Work Speaks is updated every three years, with the most recent edition covering 2009-2012. Within this most recent edition, NASW covers 64 policy issues. Given that Social Work Speaks is a reflection of our national association and thereby, our profession, we felt it pertinent to include Social Work Speaks in our review of the prevalence of explicit prevention content within social work.

In order to assess this prevalence, the word "prevention" or any direct variation, such as "preventive" or "prevent," was counted within each policy issue. This highlights the extent to which "prevention" is explicitly a matter of importance to the social work profession at the state and federal policy level. While "prevention" may often be implied and indirectly discussed within Social Work Speaks, it is likely that there is not consensus on whether a passage within the text is actually referring to "prevention," such as in the case where "early intervention" is discussed. For this investigation, only the overt presence of "prevention” language was the focus.

In completing the process, a total score (number of total times the word "prevention" or variation of the word was used) was recorded for each of the 64 policy issues. Within each policy issue, a subscore was tallied from the number of times the word "prevention"

or variation of the word was used specifically within the "policy statement" section of the policy issue. This subscore was equally important as the total score, given that the policy statement is the "call to action" section within each policy issue statement.

\section{Assessing EPAS}

To fully examine the status of prevention in social work, we must also consider how the profession educates social work students. It is within their educational programs that social work students learn about the values and goals of the profession, our holistic approach to practice, and commitment to helping vulnerable populations. For social work practitioners to adopt prevention-focused practice, social work education content must include, or even emphasize, prevention knowledge, values, and skills. The Council on 
Social Work Education (CSWE) regulates accredited BSW and MSW programs through the Educational Policy and Accreditation Standards (EPAS). As the EPAS represents the profession's regulatory mechanism regarding social work education programs, we believed it necessary to include it in our review of the current status of "prevention" in social work. As with our review of Social Work Speaks, we examined the prevalence of the word "prevention" (or any direct variation) within the current 2008 EPAS (CSWE, 2008).

\section{RESULTS}

\section{Prevention within the Social Work Literature}

The authors used a tiered search process, working from most broad to most specific. The rationale was to gauge both the breadth and the depth of the explicit prevention content within the social work literature. The first two searches were meant to assess the breadth, with the first search finding those documents that included "prevention" and "social work" anywhere in the document. This yielded 4,635 records in Social Services Abstracts, and 940 records in Social Work Abstracts. From there, the search was narrowed down to only those documents with "social work" and "prevention" in the abstract. The results, as expected, were dramatically reduced to 294 records in Social Services Abstracts and 253 records in Social Work Abstracts. The third step, used to assess the depth of explicit prevention content within the literature, included only those documents that were either journal articles or dissertations and had "prevention" and "social work" in the title of the document. By narrowing to a title-level search, only those articles with a core focus on prevention and social work were identified. There was again a dramatic drop in results at this level, with 36 records retrieved in Social Services Abstracts and 25 records in Social Work Abstracts. Within this third search step, there were some records that were found in both databases. These duplicates were identified and excluded in the results, which left 44 unique records between the two databases.

In order to examine if any trends or patterns could be established from examining those 44 records, the publication sources were identified as well as the years of publication. First looking at the publication sources, there were a total of 32 different publications (e.g., journals). Only five journals had more than one article that was found in this title-level search: Social Work in Health Care (6 articles); Health and Social Work; Journal of Social Work Education; Journal of Teaching in Social Work; and Child Welfare (each of these with 2 articles). Additionally, there were four dissertations found within Dissertation Abstracts International. The journals covered a wide range of audiences, including practitioners and academics, as well as a broad array of interest areas, including diversity, mental health, social policy, and school social work to name a few.

Second, for those 44 records found within the two databases, there was inconsistency in the trends for years of publication. Within Social Services Abstracts, there was an increase in prevention related articles over the last decade, while the opposite of this was found within Social Work Abstracts. Overall, Social Services Abstracts yielded much higher results at all three search steps than Social Work Abstracts. This can be attributed 
to the fact that the two databases have different holdings of journals and the number of journals indexed varies as well. Social Services Abstracts indexes over 1300 journals, as well as dissertations and book reviews, compared to Social Work Abstracts' collection of 400 journals (personal communication with J. Tapia, April 15, 2010). Further, Social Services Abstracts is a broader database that includes articles not only from social work and human services related journals, which is the primary focus within Social Work Abstracts, but also from those publications focused on more macro-related topics, such as social policy and social welfare, along with community development (personal communication with J. Tapia, April 15, 2010).

As a final step in examining the social work literature, it was important to conduct a similar search that served as a measure of comparison. Throughout the history of the social work profession, there has been a consistent waxing and waning dichotomy between "prevention" (e.g., public health efforts, social reform, mental health prevention) and "treatment" (e.g., clinical practice) (Trattner, 1999). As such, a search using the terms "social work" and "treatment" using the same three steps described above was conducted. As shown in Table 1, the results of this search revealed that explicit treatment content represented within the social work literature occurred 1.5 to 4 times as often as compared with explicit prevention content.

Table 1: Comparison Between "Prevention" and "Treatment" in the Social Work Literature

\begin{tabular}{llcc}
\hline Level of Search & Key Words & SWA & SSA \\
\hline Level 1: Anywhere & “social work” and “prevention” & 940 & 4,635 \\
& “social work” and “treatment” & 3,648 & 9,184 \\
Level 2: Abstract & “social work” and “prevention” & 253 & 294 \\
& “social work” and "treatment” & 1,037 & 943 \\
Level 3: Title & "social work” and "prevention” & 25 & 36 \\
& "social work” and "treatment” & 58 & 58 \\
\hline
\end{tabular}

\section{"Prevention" in Social Work Speaks}

Based on the total score for each policy issue (number of total times the word "prevention" or variation of the word was used), the issues were separated into four categories - from having "frequent" (10 or more) mention of "prevention" followed by "moderate” (3 to 9), “minimal” (1 or 2), and lastly "none”. While eight (12.5\%) of the 64 policy issues made it into the category of "frequent" with having 10 or more appearances, 24 (37.5\%) of the policy issues fell into the "minimal" category of having a total score of either 1 or 2. Surprisingly, 17 (26.5\%) of the policy issues had no explicit mention of "prevention" in the entire statement. Several of the policy issues that fell into the 
"frequent" category also had a prevalence of "prevention" in the "policy statement" sections.

The top three policy issues with both the highest total score and subscore were: school violence (23, 9, respectively), HIV and AIDS (21, 8, respectively), and youth suicide (20,6, respectively). To see if this translated into high numbers within the Social Services Abstracts and Social Work Abstracts databases, three searches, using "prevention" and "social work" along with each policy issue were used in an abstract search. The purpose of this was to determine if there was a cohesive focus regarding specific areas of prevention between NASW and scholarship. Two articles were identified with "social work," "prevention," and "school violence" in the abstract. Three articles were identified with "social work," "prevention," and "youth suicide" in the abstract, and 42 articles were identified with "social work," "prevention," and "HIV/AIDS" (38 under Social Services Abstracts and 4 under Social Work Abstracts). This demonstrates some cohesion within the HIV/AIDS arena between the social work literature and Social Work Speaks, but not within youth suicide or school violence.

Lastly, those 44 records found within the two databases that had both "prevention" and "social work" in the title were categorized according to how they related to the 64 policy issues within Social Work Speaks. Almost half of the articles were not readily identifiable as fitting into one of the policy issues. These articles did, however, fall into three identifiable topics that included: conceptualizing prevention in social work, school social work, and social work education.

\section{Prevention Reflected in our Accreditation Standards}

The 2008 EPAS contains the word "prevention" (or some variation) four times: once in the introductory section, twice in the core competencies and practice behaviors (the section that drives foundation curriculum content), and once in the standard defining generalist practice (CSWE, 2008). These four references are as follows (emphases added):

"The purpose of the social work profession is to promote human and community well-being. Guided by a person and environment construct, a global perspective, respect for human diversity, and knowledge based on scientific inquiry, social work's purpose is actualized through its quest for social and economic justice, the prevention of conditions that limit humans rights, the elimination of poverty, and the enhancement of the quality of life for all persons.” (p. 1).

Education Policy 2.1.3 Critical Thinking (under Core Competencies) ... "Social workers . . . analyze models of assessment, prevention, intervention, and evaluation ..." (p. 4).

Education Policy 2.1.10(c) Intervention (under Core Competencies) . . "Social workers implement prevention interventions that enhance client capacities . . ." (p. 7).

Educational Policy B2.2 Generalist Practice . . . "To promote human and social well-being, generalist practitioners use a range of prevention and intervention 
methods in their practice with individuals, families, groups, organizations, and communities..." (p. 7).

It is important to note here that by including prevention language under the core competencies and practice behaviors, the 2008 EPAS more or less require accredited programs to demonstrate that their students achieve competency in the prevention tasks/activities mentioned (i.e. "analyze models of prevention" and "implement prevention interventions"). For comparison, we also examined the most recent previous 2001 EPAS. The 2001 EPAS contain the word "prevention" or "preventing” twice, once in describing the purpose of the profession and once in describing the achievement of this purpose (CSWE, 2001). It is again important to note that "prevention" (or any variation) does not appear anywhere in the 2001 foundation program objectives, which are equivalent to the new core competencies and practice behaviors of the 2008 EPAS. This omission of any mention of prevention in this section implies no requirement for the inclusion of prevention content in the social work curriculum under the previous 2001 EPAS.

\section{DISCUSSION}

Policy makers at the federal and state level are demonstrating increased recognition of the need for health and mental health prevention programs and interventions (e.g., National Research Council and Institute of Medicine, 2009). Although the social work profession is uniquely positioned to promote and advocate for a prevention-focused approach to service delivery, our review indicates that there is limited focus and attention to prevention practice in the social work profession.

\section{Implications for Social Work Scholarship}

From this investigation, it is clear that scholarship that is focused on prevention in social work is limited. Of the two databases searched, Social Services Abstracts revealed an increase in prevention related articles within the last decade and Social Work Abstracts indicated a decrease. However, when the focus of these articles was more closely examined, we found that conceptual articles that advocate a prevention focus in social work have clearly decreased. These types of articles were published most frequently in the 1980s, with at least seven published during this decade (Feldman et al., 1982; Geismar \& Lagay, 1985; Germain, 1982; Libassi \& Maluccio, 1986; Roskin, 1980; Siefert, 1983; Whitman \& Hennelly, 1982). Our search revealed no other conceptual articles published until 2006 (Hawkins, 2006; Woody, 2006). Other articles published between the 1980s and 2006 with "prevention" and "social work" in the title were all area-specific (e.g. delinquency prevention; school-based prevention; teen pregnancy prevention). The lack of conceptually focused articles in the last two decades suggests that there has been little debate or consideration among social work scholars regarding the connection between prevention and social work during this time period.

Increasing prevention-focused scholarship would facilitate further debate regarding the role of prevention in the social work profession. This could be done in a number of ways. Editors of journals could increase their efforts to encourage prevention-related 
content by creating a Special Issue on the topic. Editors could also use explicit prevention-focused language in the routine calls for papers, within the online "aims and scope" description of their journals, and within their instructions for authors. Additionally, we encourage all editors to review their journal's past table of contents and to assess whether prevention related articles are being published, and if not, to examine why. Further, our national conferences hosted by the Society for Social Work and Research (SSWR), CSWE, and Baccalaureate Program Directors (BPD) could add a "prevention in social work" track or add explicit prevention language into the call for abstracts.

In addition, mentorship is critically important for junior scholars whose focus is prevention within social work, regardless of population of interest. In order for prevention to receive a greater emphasis, prevention-focused scholars and practitioners will need to define a distinct knowledge base and skill set for those interested in this area of social work. This may be difficult, given the lack in prevention-focused content in social work education and possible lack of recognition of "prevention" as a legitimate area of research within social work. This supports the need for mentorship, both informal and formal. While helpful email listservs, such as the Early Career Preventionists Network (ECPN), sponsored by the Society for Prevention Research (SPR) exist, it seems likely that social workers could benefit from a similarly formed social network that connects scholars interested in social work and prevention.

We assert that prevention should be an equally important focus as treatment within the profession, with evidence reflected in the social work literature. Currently, there were 74 unique records found in Social Service Abstracts and Social Work Abstracts when searching "social work" and "treatment" within the title. This compares to 44 unique records found when searching "social work" and "prevention." This represents a clear benchmark that can be set for the near future.

\section{Implications for Social Work Practice}

If NASW's Social Work Speaks can be viewed as a window into where our profession is focused in current social policy and practice issues, then prevention is clearly not a core element of many areas of social work practice. Review of the most recent Social Work Speaks indicates a lack of explicit prevention language in policy issues addressed, particularly in the "policy statement" sections. It was surprising that more than $25 \%$ of the policy issues covered had no explicit mention of prevention, especially in issues such as: 1) poverty and economic justice, 2) rural social work, 3) people with disabilities, and 4) prostituted people, commercial sex workers and social work practice. These are areas in which it seems clear that prevention should play a role in practice, as well as policy formation and advocacy. For poverty and economic justice, practitioners who are engaged in policy practice can advocate for social welfare policies that will prevent increased percentages of those in poverty (e.g., raising the federal minimum wage). Practitioners in rural areas can focus on the prevention of social problems that are particularly prevalent in rural locations because of isolation and lack of access to care, such as teen pregnancy (Skatrud, Bennett, \& Loda, 1998). Prevention in the area of disabilities can include a focus on advocating for inpatient substance abuse 
treatment centers to admit pregnant women as a way to prevent fetal alcohol syndrome, which is the leading cause of mental retardation (Hutchison, 2008). For the last issue mentioned, sex trafficking and prostitution, it is acknowledged that as long as there is a demand for sex-work there will always be a supply. However, prevention efforts can focus on increasing access to condoms, as well as HIV counseling and testing for sex workers (Rekart, 2005). It seems reasonable that a benchmark of adding explicit prevention language into the 17 policy issues currently lacking any mention of prevention for the next edition of Social Work Speaks could be reached.

The review of Social Work Speaks also suggests a gap between practitioners and scholars, particularly in the disconnect between research and practice in areas such as youth suicide and prevention as well as school violence and prevention. Both of these policy statements emphasized prevention in Social Work Speaks. There was little attention to these areas, however, in the social work literature. A Special Issue in a related journal could address these issues easily.

\section{Implications for Social Work Education}

Review of the current (2008) and previous (2001) EPAS indicates a slight increase in prevention language, with explicit prevention language used twice in the 2001 EPAS and four times in the 2008 EPAS. More importantly, the fact that prevention language is included in the core competencies and practice behaviors of the current EPAS suggests that social work programs will need to demonstrate that graduating students are competent in analyzing and utilizing prevention models with clients. This may be a challenge as prevention is typically not a primary focus of social work education programs. For the profession to move forward in the area of prevention-focused practice, however, educational content in social work programs must include, or even emphasize, prevention knowledge, values, and skills. This can occur in two different ways. One identifiable mechanism is through accreditation/reaffirmation. The self-study requirement for reaffirmation provides an excellent opportunity for program directors and faculty to thoroughly examine the curriculum for prevention-focused content in each of the courses. As course objectives are written to fit the core competencies and practice behaviors that are associated with each course, faculty responsible for these objectives can consider incorporating one objective that emphasizes prevention-focused content. A second way in which prevention-focused content can be incorporated into social work curriculum is to first create an elective that has a prevention focus as the overarching theme for the class (e.g., Children's Mental Health or Sexual Health). This allows programs to gauge the interest level of students as well as provide time for faculty to determine how they would start integrating prevention-focused content into other required courses and electives.

Of course, faculty will need to embrace the idea that prevention-focused content is a priority before any program-wide change occurs. As faculty become committed to integrating prevention-focused content, Siefert, Jayaratne, \& Martin (1992) and more recently Woody (2006) offer specific recommendations for developing and implementing prevention-focused content into generalist and advanced social work courses and programs. Siefert and colleagues describe the development of three specialized prevention courses created within a public health conceptual framework aimed at 
strengthening social workers' preparation in prevention practice. Woody (2006) provides specific guidelines for integrating prevention principles and practices, as well as models of prevention services, into the social work curriculum. The ten specific principles discussed include ideas such as teaching skills related to the identification of both risk and protective factors, risk screening and risk reduction practices, and community capacity building. Finally, Lurie and Monahan (2001) suggest eight specific prevention practice principles for social workers practicing in the area of mental health, which could be used as a starting point for developing prevention-focused curriculum content within courses focused on mental health and clinical practice.

\section{Limitations of Investigation}

Several limitations of this study should be noted. Most notably, the authors made a conscious decision to choose the literature, the EPAS standards, and the NASW Social Work Speaks, to serve as the indicators in this investigation. These indicators are not exhaustive and there are certainly other indicators, such as academic and practice job posting descriptions, the number of social work programs with a joint MSW/MPH option, and so forth. The three indicators were chosen both because they were deemed appropriate for the research question at hand, and the information needed to assess them was easily accessible.

Another limitation that relates specifically to using the social work literature as one of three indicators is that the number of articles within the two databases, Social Work Abstracts and Social Service Abstracts, is constantly in flux. Consequently, the numbers that are presented in this manuscript will inevitably vary as compared to what would be found if the search were conducted at another point in time. However, it is unlikely that the numbers will experience a dramatic shift within the near future.

Finally, the authors have made a conclusion that social workers ultimately can and should become more effective in integrating prevention into social work scholarship, practice, and education. That said, it is also worthwhile to note that it is likely that social workers are, in fact, engaging in prevention-focused research, teaching, and practice, but there is not a viable and systematic mechanism for identifying and tracking those activities.

\section{WHAT IS THE FUTURE OF PREVENTION AND SOCIAL WORK?}

In conclusion, our scholarly literature, along with our educational and professional guidelines, seems to lack both focus as well as integration in explicit prevention content. What may be needed is a break from "business as usual" (i.e., a treatment-only philosophy). This can be done first and foremost through social work education by encouraging deans and chairs of social work programs across the country to initiate discussion among social work faculty regarding integrating prevention content throughout the curriculum. The new 2008 EPAS support this by requiring programs to demonstrate student competency in implementing prevention models. Current practitioners must also be educated on prevention principles, knowledge, and skills. Continuing education classes may be one way to achieve this goal. Additionally, social 
service organizations can make a commitment to increase opportunities for social work interns to foster an interest in prevention-focused activities. Most importantly, as a profession, we need to agree that prevention is valuable and is at the heart, not the fringe, of our profession. Prevention offers savings in financial costs, promotes physical and mental well-being of our clients, and may even be beneficial to social workers who are struggling with managing the ever revolving door that comes with treatment-only practice. It is clearly an ideological issue that our profession must confront in the coming years.

\section{References}

Ager, R. D., Parquet, R., \& Kreutzinger, S. (2008). The youth video project: An innovative program for substance abuse prevention. Journal of Social Work Practice in the Addictions, 8, 303-321.

Beardslee, W. R. (1998). Prevention and the clinical encounter. American Journal of Orthopsychiatry, 68, 521-533.

Bracht, N. (2000). Prevention: Additional thoughts. Social Work in Health Care, 30, 1-6.

Brashear, D. B. (1976). The social worker as sex educator. Hampstead, NY: SIECUS.

Bronfenbrenner, U. (1979). The ecology of human development. Cambridge, MA: Harvard University Press.

Coie, J. D., Watt., N. F., West, S. G., Hawkins, D., Asarnow, J. R., Markman, H. J., Ramey, S. L., Shure, M. B., \& Long, B. (1993). The science of prevention: A conceptual framework and some directions for a national research program. American Psychologist, 48, 1013-1022.

Council on Social Work Education. (2008). Educational policy and accreditation standards. Available at http://www.cswe.org/File.aspx?id=13780.

Council on Social Work Education. (2001). Educational policy and accreditation standards. Available at http://www.cswe.org/File.aspx?id=14115.

Deschin, C. (1968). The future of social work: From concern with problems to emphasis on prevention. American Journal of Orthopsychiatry, 38, 9-17.

Dulmus, C. N., \& Wodarski, J. S. (1997). Prevention of childhood mental disorders: A literature review reflecting hope and a vision for the future. Child and Adolescent Social Work Journal, 14, 181-198.

Durlak, J. A. (1998). Common risk and protective factors in successful prevention programs. American Journal of Orthopsychiatry, 68(4), 512-520.

Farmer, T. W., \& Farmer, E. M. Z. (2001). Developmental science, systems of care, and prevention of emotional and behavioral problems in youth. American Journal of Orthopsychiatry, 71, 171-181.

Feldman, R., Stiffman, A., Evans, D., \& Orme, J. (1982). Prevention research, social work, and mental illness. Social Work Research \& Abstracts, 18, 4-13. 
Garmezy, N. (1985). Stress resilient children: The search for protective factors. In J. E. Stevenson (Ed.), Recent research in developmental psychology: Journal of child psychology and psychiatry book (pp. 213-233). Oxford, UK: Pergamon.

Geismar, L. L., \& Lagay, B. W. (1985). Prevention in social work: a postmortem of an experiment on preventive intervention. The Journal of Applied Behavioral Science, 21, 329-338.

Germain, C. (1982). Teaching primary prevention in social work: An ecological perspective. Journal of Education for Social Work, 18, 20-28.

Gilbert, N. (1982). Policy issues in primary prevention. Social Work, 27, 293-297.

Hawkins, J. D. (2006). Science, social work, prevention: Finding the intersections. Social Work Research, 30, 137-152.

Hutchison, E. D. (2008). Dimensions of human behavior ( $3^{\text {rd }}$ ed.). Los Angeles, CA: Sage Publications.

Kellam, S. G., Koretz, D., \& Moscicki, E. K. (1999). Core elements of developmental epidemiologically based prevention research. American Journal of Community Psychology, 27, 463-482.

Libassi, M. F., \& Maluccio, A. N. (1986). Competence-centered social work: prevention in action. The Journal of Primary Prevention, 6, 168-180.

Lurie, A., Monahan, K. (2001). Prevention principles for practitioners: A solution or an illusion? Social Work in Health Care, 33, 69-86.

McCave, E. L. (2010). "It is not just about me”: A relational understanding of young women's sexual negotiations. Smith Studies in Social Work, 80, 53-69.

Mrazek, P. J., \& Haggerty, R. J. (Eds.) (1994). Reducing risks for mental disorders: Frontiers for preventive intervention research. Washington DC: Institute of Medicine, National Academy Press.

National Association of Social Workers. (2010). Code of ethics. Washington, DC: Author.

National Association of Social Workers. (2009). Social work speaks. Washington, DC: NASW Press.

National Research Council and Institute of Medicine. (2009). Preventing mental, emotional, and behavioral disorders among young people: Progress and possibilities. Committee on Prevention of Mental Disorders and Substance Abuse Among Children, Youth and Young Adults: Research Advances and Promising Interventions. Mary Ellen O’Connell, Thomas Boat, and Kenneth E. Warner, Editors. Board on Children, Youth, and Families, Division of Behavioral and Social Sciences and Education. Washington, DC: The National Academies Press.

Rapoport, L. (1961). The concept of prevention in social work. Social Work, 6, 3-12.

Rekart, M. L. (2005). Sex-work harm reduction. The Lancet, 366, 2123-2134. 
Rice, E. (1962). Concepts of prevention as applied to social work practice. American Journal of Public Health, 52, 266-74.

Rishel, C. W. (2007). Evidence-based prevention practice in mental health: What is it and how do we get there? American Journal of Orthopsychiatry, 77, 153-164.

Rosendberg, G., \& Holden, G. (1999). Prevention: A few thoughts. Social Work in Health Care, 28, 1-11.

Roskin, M. (1980). Integration of primary prevention into social work practice. Social Work, 25, 192-196.

Shore, M. F. (1998). The making, unmaking, and remaking of primary prevention. Journal of Mental Health, 7, 471-477.

Siefert, K., Jayaratne, S., \& Martin, L. D. (1992). Implementing the public health social work forward plan: A research based prevention curriculum for schools of social work. Health and Social Work, 17, 17-27.

Siefert, K. (1983). An exemplar of primary prevention in social work: The SheppardTowner Act of 1921. Social Work in Health Care, 9, 87-103.

Skatrud, J. D., Bennett, T. A., \& Loda, F. A. (1998). An overview of adolescent pregnancy in rural areas. The Journal of Rural Health, 14(1), 17-27.

Skiba, D., Monroe, J., \& Wodarski, J. S. (2004). Adolescent substance abuse: Reviewing the effectiveness of prevention strategies. Social Work, 49, 343-353.

Smith, C., \& Carlson, B. E. (1997). Stress, coping, and resilience in children and youth. Social Service Review, 72, 231-256.

Trattner, W. I. (1999). From poor law to welfare state: A history of social welfare in America (6 ${ }^{\text {th }}$ ed.). New York: The Free Press.

Walsh, J. A. (1982). Prevention in mental health: Organizational and ideological perspectives. Social Work, 27, 298-301.

Whitman, B. Y., \& Hennelly, V. D. (1982). The use of epidemiologic methods as the bridge between prevention and social work practice. Social Work in Health Care, 7, 27-38.

Woody, J. D. (2006). Prevention: Making a shadow component a real goal in social work. Advances in Social Work, 7, 44-61.

Yampolskaya, S., Brown, E. C., \& Vargo, A. C. (2004). Assessment of teen pregnancy prevention interventions among middle school youth. Child and Adolescent Social Work Journal, 21, 69-83.

\section{Author note:}

Address correspondence to: Emily L. McCave, West Virginia University. PO Box 6830 Morgantown, WV 26506 Email: elmccave@mail.wvu.edu 